\title{
Activism and Rhetoric
}

Theories and Contexts for Political Engagement

\section{Edited by JongHwa Lee and Seth Kahn}

First published 2010

ISBN 13: 978-1-138-50170-6 (hbk)

ISBN 13: 978-1-138-50171-3 (pbk)

ISBN 13: 978-1-315-14453-5 (ebk)

\section{Chapter 1}

\section{Borders of Engagement}

Rethinking Scholarship, Activism, and the Academy

Bryan J. McCann

CC BY-NC-ND 4.0

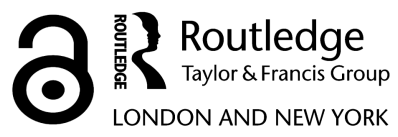




\title{
1 Borders of Engagement Rethinking Scholarship, Activism, and the Academy
}

\author{
Bryan J. McCann
}

During the 2010 National Communication Association (NCA) Convention, I walked down a San Francisco street with a senior colleague/mentor. For the second time in three years, NCA was immersed in a labor dispute. The union UNITE HERE! had called a boycott of one conference hotel and, like the contentious 2008 San Diego convention, several members wished to honor the boycott. Presumably learning from the 2008 fiasco, NCA secured space to hold sessions outside the disputed hotel. Still, several NCA members worked with local labor activists to coordinate media coverage and picketing during the conference. While responses from colleagues opposed to the boycott were not as intense as 2008, some did make clear their frustration. In addition to the usual venues for these debates, for example, the organization's national email list (CRTnet), some members chose more confrontational behaviors: for instance, during the picket at the hotel, a conference attendee seized a stack of leaflets from another NCA member's hands and threw them in the trash. ${ }^{1}$

In this context, I walked with my colleague, who had provided careerrelated guidance before. As we parted ways-he was entering the boycotted hotel; I was not-he asked if I thought my public participation would impact my job prospects. I was a non-tenure-track faculty member at a small liberal arts school, seeking a tenure-track appointment at an institution with a graduate program. The question took me off guard, not only because of the power imbalance with this colleague, who also wrote me recommendation letters, but also because it was a rare, if subtle, expression of our disagreement regarding the politics of boycotting NCA. I said I hoped not; I never kept my activism a secret relative to my professional identity. I also explained that I hoped my scholarship and teaching spoke for themselves and would be the primary basis on which prospective employers judged me. My colleague agreed, but added that some individuals at institutions where I had applied contacted him with concerns about my conspicuous involvement in the boycotts. He claimed that he advocated for me but wanted me to be aware that such concerns lingered. We concluded the conversation and parted ways.

Even before 2010, I had begun crafting a professional identity as an activist rhetorician, an engaged scholar. During graduate school in Texas, I participated 
in anti-death penalty organizing and other struggles that resonated with my scholarly interests in criminality and race. The fact that I did recognizable activist work (meetings, literature tables, demonstrations), occasionally appeared on the news, and even participated in civil disobedience helped me cultivate the image of a scholar who practiced what he preached. Also, to be clear, the cache associated with my activism was largely a function of my occupying a white cismasculine body and agitating around matters that, while controversial in the conservative state of Texas, resonated with the mainstream liberal sensibilities of my colleagues. Numerous people of color, women, LGBTQ+ individuals, religious minorities, and people living at the intersections of these identities and more, as well as outspoken scholars on polarizing matters such as Palestinian liberation, have paid dearly for their activism (e.g., Steven Salaita; also see Cloud, this volume). For me, doing activism outside the academy and contending that my activism, scholarship, and teaching mutually informed each other seemed to help more than it hurt.

What made boycotting a conference hotel different? Why did activism directed away from my campus and professional organization inspire praise from colleagues, while actions that risked disrupting a disciplinary gathering provoked anger and confrontation from strangers, and microagressive behavior from mentors? My contention is that actions such as the 2008 and 2010 NCA boycotts did not exclusively, or even primarily, ask communication scholars what we could do to solve a problem - the domain of increasingly hegemonic modes of "engaged scholarship." Instead, these boycotts required us to reckon with the ways we-as scholars whose assembly relies on the labor and capital of others - are part of the problem. This, I believe, was the primary trigger for the fallout before, during, and after the 2008 and 2010 conventions, and represents a broader anxiety associated with prevailing definitions of engaged scholarship.

The rhetorical norms around scholarly engagement presume that scholars participate in activist work outside their professional spaces. The avatar of the activist-scholar is the energetic graduate student who fulfills their academic responsibilities while also pursuing activist interests in the "community." Other models of engaged scholarship call for even more explicit connections between traditional professional responsibilities and communities outside the boundaries of the academy. The community, as constituted in most professional discourse regarding engaged scholarship, exists outside the walls of the campus, or our professional organizations and conferences. As Gunn and Lucaites observe, "In general, the call for the academic to engage socially reduces to the mandate that scholars and teachers make their work relevant, informative, or empowering to communities or publics outside of the (often erroneously assumed) confines of the college or university" (409). They add that the call to engage presumes a traversal of the boundaries between campus and community.

I want to trouble such boundaries not by calling for more engagement off campus, but instead for a turn inward. Specifically, I argue the presumption that activist rhetoricians and other scholars must traverse the border between academy and community reifies the border between the engaged scholar and 
academia itself. Privileging the community as a vulnerable space outside the academy creates an alibi for the structures of higher education themselves. Campuses and academic organizations are sites of cruelty that disproportionately harm underrepresented populations - they are places where labor is exploited (e.g., Birmingham), free speech and academic freedom are violated (e.g., "Academic Freedom and Tenure"), senior scholars haze, harass, and otherwise abuse colleagues and students (e.g., Ortiz), white supremacy inflicts indignities and violence on racialized bodies (e.g., Bauer-Wolf), and many colleagues and administrators cooperate with state and corporate actors engaged in various modes of injustice (e.g., Arkin and O'Brien). Most of us know these problems exist; yet one rarely finds them in our journals or conference sessions when the topic is engaged scholarship. The very scholars who espouse engaged scholarship outside the academy often benefit from the injustices that occur therein. Others - specifically, those to whom this chapter is directedhave never been encouraged to imagine campuses or academic organizations as communities that need attention. One of the most important roles activist rhetoricians can play in addressing the injustices that occur before our eyesin classrooms, thesis/dissertation defenses, departmental meetings, conference hotel bars, or elsewhere-is denaturalizing the stories we tell about ourselves and our institutions. We should subvert the bordering practices that separate the materiality of academia from its own calls for engagement and social justice. By critiquing the rhetorics of engagement that prevail in communication studies, I proceed in this chapter to identify the bordering practices of engaged scholarship, detail the ways in which such practices protect the cruelty of academic institutions, and conclude by suggesting ways of imagining academic activism that traverse the borders of engagement and activate the spaces in which we labor.

\section{Bordering Practices and Engaged Scholarship}

Rhetorical studies, and higher education generally, have always to some degree been invested in traversing the campus-community border. Rhetorical studies, both its communication and composition manifestations, came of age alongside the land grant movement. Our founding charge was to train (white, predominantly cisgender male) poor and working-class populations in the arts of eloquence in the service of crafting ethical and professional citizen-subjects (Gehrke). While not without critics (e.g., Chávez, "Beyond Inclusion”), this ethic provides a historical starting point for mapping the investments that mobilize our prevailing contemporary models of engagement. In short, calls to be engaged almost always entail calls to cross the border, to step down from ivory towers and get our hands dirty in the muck of "real life."

We can imagine the boundary between academy and community as a border. I draw on a body of rhetorical scholarship that primarily attends to bordering practices at the frontier between Mexico and the United States. However, 
as scholars such as Anzaldúa and Chávez (“Queer Migration”) argue, borders manifest in various contexts and condition bodies and communities in consequential ways. At core, borders are constituted and enforced through rhetoric, as well as brute force. As Cisneros writes, "Rhetorics of the border not only define spatial relations but also materialize the boundaries of belonging" (7). Bordering practices police and regulate acts and bodies that do not adhere to norms associated with citizenship, whether national or disciplinary (also see, e.g., Flores, "Constructing Rhetorical Borders").

The bordering practices occurring vis-à-vis migration between Mexico and the United States are often deadly for racialized bodies who transgress the border. I am not implying a clean homology between those bordering practices and ours in the academy. I am arguing that the critical protocols associated with bordering provide heuristics for interrogating the rhetorical norms regarding engaged scholarship — what we might call normative academic citizenship — and illuminate the ways such practices disproportionately harm already-vulnerable bodies laboring and learning on our campuses and in our organizations.

The most striking rhetorical move associated with hegemonic models of engaged scholarship is the production of borders in order to transgress them. The presumption that academic engagement requires violating the border between academy and community demands a border between academic engagement and the academy itself. For example, commenting on the rationale behind the 2016 NCA annual convention theme, "Communication's Civic Callings," then-President Hartnett ("Putting NCA's") wrote,

Hoping to empower a generation of scholars who look beyond the traditional ivory tower for their inspirations, collaborators, and community projects, the theme pointed to the intersections of teaching, research, and service, where we utilize our Communication theories and practices to speak to, learn from, and work alongside practitioners who are tackling the urgent needs of local, national, and international communities. (2)

Hartnett, who has dedicated much of his career to engaging communities, especially incarcerated individuals (e.g., Hartnett, "Lincoln and Douglas"), not traditionally represented in academic spaces, added that the conference theme sought to empower scholars "who seek to respond to the desperate needs of communities that are not traditionally represented at the convention or in our scholarship" (2). The articles that follow Hartnett's opening editorial in the issue of NCA's newsletter Spectra profile a variety of projects spearheaded by communication scholars who engage in research, teaching, and service that address deeply salient needs outside the academy (e.g., Enck). While a contribution from Whitehead explicitly centers the communication classroom (and other contributors address the salience of communication pedagogy vis-à-vis activism) as a site of engagement and consciousness-raising, none address the academy itself as a site requiring intervention from communication scholars. In the same issue, Frey, who is deeply influential in the realm of engaged scholarship, 
draws a firm line in the sand when he writes, "Engaged (Communication) scholarship, thus, represents an important tectonic shift from insular disciplinary research and corporate education to the involvement of researchers, educators, and students with nonacademic community" (10). For Frey, such a scholarly move represents a return to the founding principles of US higher education: a commitment to serving communities surrounding campuses, and a rejection of insularity and corporatization.

I do not wish to imply that Hartnett, Frey, or others who call for work that engages with non-academic communities are apathetic to the harms that occur on campuses and within academic organizations. Rather, I see their rhetoric as part of a broader bordering project that explicitly transgresses the border between the academic and the non-academic, while simultaneously affirming the border between engaged scholars and the academy. Neither Frey nor Hartnett minces words when they call on scholars to turn away from the "ivory tower" and toward the non-academic community. Furthermore, in a 2010 Quarterly Journal of Speech forum dedicated to the topic of engaged scholarship, all contributors approached the question of engagement as a matter of scholars intervening outside the academy. For example, John McGowan proposes that colleges and universities rethink their evaluation standards for faculty by asking professors to identify the communities who benefit from their work and, when making determinations about promotion and other areas of evaluation, consulting those communities about the scholar's impact. ${ }^{2}$ I wonder, pessimistically, whether such a transformation in evaluative standards would incentivize scholars who hold colleagues accountable for their predatory behaviors, disrupt faculty searches that do not actively seek to create a diverse candidate pool, or promote policy changes at the departmental, college, and university level that threaten the hierarchies atop which many faculty and administrators believe they have spent their careers earning a place. Because borders are in the business of marking and enforcing the norms of citizenship, and because such norms are never neutral in terms of whose interests they serve, it is highly unlikely that such interventions at the level of the academic institution would generate the same kind of enthusiasm-indeed, they are more likely to provoke hostility - as an activist-scholar who works with populations in nonacademic communities. The rhetoric of engaged scholarship, in other words, partakes in bordering practices that mobilize scholars' activist energies toward a pre-figured model of the non-academic community and away from the cruelty of the academy itself.

\section{The Academic Politics of Cruelty}

The smile then is a kind of social reflex; we smile in identifying-even if involuntarily or momentarily - with the society which force has brought into being. 
Borders are built to protect ways of life. The Mexico-US border, for example, protects the heteronormative modes of whiteness that constitute US national identity (Chávez, "Queer Migration”). The bordering practices of engaged scholarship protect the politics of cruelty that are the norm in US higher education. Cruelty is capable of intoxicating us, numbing us, and commanding our allegiance (Millet). Bystanders read erotic pleasures into images of cruelty and easily become complicit in cruel acts through acquiescent smiles, as noted in the above epigraph, or "the incentives of increased status, privilege, and rewards" (Millet 304-5). We frequently equate cruelty with rigor, so the suffering associated with academic labor becomes necessary to academe's prized value. During my faculty career, mostly spent at PhD-granting institutions, I have lost track of how often I hear senior colleagues wax nostalgic about how hard it was to advance, and in so doing, rationalize inaction regarding the difficulties graduate students and junior (much less adjunct) colleagues face. Full professors have told me that graduate school is boot camp or that hierarchy is inevitable in of academic life. A pre-tenure colleague told me that, during their annual review, the department chair claimed that one should never expect the academy to be humane and that expecting a balanced life, at least before tenure, is unrealistic. My colleagues made these comments without explicit irony or regret - this is simply the way it is.

While I do not wish to draw facile homologies between the corporeal acts of torture Millett documents and the indignities of academic labor, I do believe her work illuminates the forms of cruelty the bordering practices of engaged scholarship protect. The academy is a cruel place (Baker) and acts of cruelty give expression to the joys of occupying positions of power and privilege (e.g., Levina). If our operative definitions of engaged scholarship disparage the "ivory tower" as a site of activism, they orient our attention away from the targeting of our colleagues for retaliation and hazing or the ways our curricular, teaching, hiring, and editorial practices exclude historically marginalized groups. Such definitions, and the bordering practices they mobilize, are therefore complicit in cruelty.

The pain permeating every level of academia is well-documented. Virtually all academic units, including those in the critical humanities, rely on the exploitation of contingent faculty and graduate students (e.g., Birmingham). The academic job market is a cruel space where tenure-track positions are increasingly rare, meaning more new graduates and junior scholars must compete for fewer relatively secure academic jobs. Furthermore, despite espoused commitments to hire more people of color and members of other marginalized groups for faculty positions, institutions continue to privilege whiteness through hiring practices. Even tenure-track positions, particularly at universities that prioritize high scholarly output, and especially for members of underrepresented communities, are often agonizing as expectations fluctuate and new analytics enter the evaluative picture. Whereas tenure is nominally designed to protect academic freedom, it has increasingly become a devil's bargain demanding 
six years of physically and psychologically damaging pressure in pursuit of job security. Worse, today's junior faculty are often evaluated by senior colleagues who did not face the same tenure expectations, but demonstrate few qualms about holding others to such standards (see Dutta; Sensoy and DiAngelo). While such experiences do not rise to the standard of torture as chronicled in Millett's work, they are cruel.

Furthermore, Millett's observations about complicity resonate deeply with the culture of cruelty in the academy. Many of us, particularly those with tenure, treat the cruelties of the academy as the price of admission; part of a cycle of cruelty that renews with each new cohort of graduate students and new faculty hire. We often smile knowingly, sometimes out of pity and sometimes nostalgic amusement, at our colleagues' struggles. Furthermore, we are rarely inclined to disrupt a system cruel as it may be, in which we feel we have earned our place. To disrupt the cycle of cruelty may require sacrifice from those of us with the most "status, privilege, and rewards" (Millet 305). As Danielle Allen demonstrates in her studies of citizenship, sacrifice is a precondition of progress, and typically the privileged are least willing to sacrifice.

I want to be clear that these cruelties do not fall evenly upon all bodies and that I am by no means the first scholar in our field to scrutinize such cruelty. People of color, and especially women of color, have published compelling and devastating scholarly works that draw on the racialized and gendered indignities of the academy. For white cisgender masculine scholars such as myself, the needs associated with academic life often do not feel desperate or urgent, and the status quo often benefits us. Furthermore, higher education, particularly state institutions, face staggering crises of legitimacy and fiscal solvency (e.g., Newfield). The prospect of openly critiquing our departments, campuses, and organizations may strike scholars as foolhardy when our vulnerability is so palpable. Where precarity may be a new condition to privileged academics, it is familiar to many others. Thus, we who write on matters of engagement from positions of privilege need to listen to our less-privileged colleagues who challenge the bordering practices of academic engagement.

For example, in her monograph on monstrosity in public culture, Calafell reflexively narrates/describes the ways her white and cisgender male colleagues figure her, a queer Latina feminist, as a monster. Calafell illuminates the ways the racialized and gendered figure of the monster circulates in academia just as surely as in popular horror films. Scholars such as Ahmed, Brenda Allen, Chávez ("Beyond Inclusion"), and Davis have also invoked the concrete practices of the academy to make broader theoretical claims about the cultural politics of race and gender. Furthermore, many colleagues publicly engage in matters of controversy at their institutions-sometimes at considerable cost to their careers and health - or use their leadership positions in academic organizations to advocate for progressive changes in higher education itself (e.g., Hill). Such work, while undeniably working within an activist register, does not accord 
with prevailing definitions of engaged scholarship. Rather, the bordering practices of engagement constitute them as non-normative relative to ideal activist scholarship (i.e., work outside the "ivory tower") and thus marginalize activist work that seeks to improve the lives of vulnerable individuals (i.e., those not traditionally represented at our conferences or in our scholarship) who teach, learn, and labor on our campuses.

Along with explicitly naming the cruelty that permeates our campuses and academic organizations, scholars at the margins of rhetorical studies challenge the border between the prevailing standards of engaged scholarship and accompanying understandings of community. Authors such as Asante, Blair ("Contested Histories"), Campbell, Flores ("Creating Discursive Space”), Houston, Morris and Nakayama, Ono and Sloop, and many others have affirmed the legitimacy of marginalized voices in rhetorical studies, helping to create space for younger scholars who found little resonance with canonical politics that still prevail in rhetoric (see Calafell, "Rhetorics of Possibility"). Thus, the bordering politics of engaged scholarship, by investing in a firm distinction between academic labor that invests in the "ivory tower" on one hand, and the non-academic community on the other, ignore and often denigrate the value of scholarship as such as a mode of activism for marginalized bodies within the academy.

The espoused goal of engaged scholarship, particularly as expressed in communication, is to draw on academic expertise to address the "urgent needs" (Hartnett 2) of specific communities. I hope the last few paragraphs, while barely scratching the surface, suffice to demonstrate the many needs within academia, or what "engaged scholars" often dismiss as "the ivory tower." We who labor in the academy do so in a space of cruelty - to which all of us, to varying degrees, are both subject and complicit. However, the most hegemonic models of engagement, in their efforts to cross borders between academic and non-academic communities, produce a border between the figure of the engaged academic and academia itself. Such bordering practices normatively define engagement in ways that excuse the politics of cruelty that permeate our workplaces and, by failing to include work that addresses the academy as a site that needs engagement, provides cover for colleagues and administrators who seek to discipline those already-vulnerable scholars who disrupt academia's status quo. In the following section, I advance ways we might transgress the border politics of engagement and confront the everyday cruelties of the academy.

\section{Traversing Borders and Resisting Cruelty through Embedded Activist Rhetoric}

To distance oneself professionally through critique, is this not the most active consent to privatize the social individual?

Stefano Harney and Fred Moten 
Engaging with academic spaces is not sexy. Much of the cruelty on our campuses and in our professional organizations operates in ordinary contexts such as department and committee meetings, classrooms, evaluation processes, and other sites of academic labor that many of us regard as distractions from the passions that led us to higher education. The conventional wisdom is that service is a tertiary commitment relative to teaching and writing. However, precarious as it may be, shared governance is one of the most valuable modalities through which we might reimagine our relationships to our institutions and our understandings of engaged scholarship. Just as the factory worker of Marx and Engel's Europe possessed the capacity to halt production and make demands on the boss, so too are many academics equipped to leverage governance and service to transform and, when necessary, disrupt operations in our departments, on our campuses, and at our annual conventions. But before outlining what such work may look like, let us reconceptualize engagement in ways that traverse the current borders between the engaged scholar and the site of cruelty in which they labor.

As I have argued, prevailing understandings of engaged scholarship figure the academy as a depository of activist intellectuals who should orient their talents toward communities-in-need. Those who work within the realm of the academy are often dismissed by engaged scholarship's champions as "producing works about tendential subjects for miniscule audiences engaged in no real-world struggle" (Hartnett, "Communication, Social Justice" 72) or, for those engaged in explicitly critical (but not "engaged") work, positioning themselves as "High Priests of Knowledge who, while not speaking as activists in their own right, transferred the necessary skills, tools, and motivation to other actors" (78). But, as I note earlier, scholarship drawing on theoretical traditions and centering the experiences of traditionally marginalized populations creates space for other scholars, particularly those from historically underrepresented communities in the academy, to do the same (see Flores, "Between Abundance"). And even if a scholar never writes an explicitly political word, that scholar is not precluded from supporting colleagues and students experiencing the cruelties of the academy, engaging in self-advocacy, or working with others to transform the workplace. One need not be a "critical" or "engaged" scholar in rhetoric to perform activist work in the academy. When we operationalize engagement so that scholaractivists' activism must correspond with their other professional work, we further entrench the bordering practices that characterize prevailing models of engaged scholarship.

To disrupt the border between engagement and the academy, we should turn our attention to the embeddedness of the academic laborer as such. This includes rhetoricians, as well as our colleagues in STEM fields and other domains - including non-academic laborers on our campuses. As I argue later, we also must understand that all coalitions are contingent and that colleagues are often the problem, rather than the solution. ${ }^{3}$ Such critical orientations toward the academy and the bordering practices that divide it from the practice 
of engagement require attention to our embeddedness in the materiality of academic institutions. Jack Bratich argues that academic labor is fundamentally embedded, and that critical or activist intellectuals are charged with reappropriating such positionality. Many intellectuals are already entrenched in industries that poison the planet, military projects that murder and displace legions, and carceral policies that surveil and confine vulnerable populations. Bratich calls on intellectuals to embed themselves in "collaborative projects of exodus and refusal" (34). Similarly, Stefano Harney and Fred Moten call on us to abuse the academy's hospitality. They explain that "it cannot be denied that the university is a place of refuge, and it cannot be accepted that the university is a place of enlightenment" (26). For them, academia (I take the liberty of including academic organizations) can never be entrusted to foster modes of critical practice that threaten its own status quo or that of civil society. Harney and Moten, that is, reject the presumption that universities are incubators for social justice (also see Loick). But they do not want to abandon the university wholesale. Rather, Harney and Moten encourage us to take advantage of its resources and privileges in order to constitute networks of affinity that they call the undercommons.

With the caveat (I will elaborate shortly) that some of us can afford these lines of flight more than others, I find Harney and Moten's work instructive for destabilizing the bordering practices of engaged scholarship. They write, "Certainly, critical academic professionals tend to be regarded today as harmless intellectuals, malleable, perhaps capable of some modest intervention in the so-called public sphere" (32). If we accept Harney and Moten's claim (I believe we should) that the institutions coalescing as the academy are hopelessly tethered to the state and capital, then we should recognize the limits of leveraging the academy to make transformative interventions in civil society. I am not suggesting that we should immediately cease writing scholarship, developing curriculum, or participating in service that positively impacts communities outside academia's borders. Rather, I am suggesting that such work will always be limited due to its entrenchment within the academy and that the most potent agency of activist academics is their embeddedness within the academy itself. Making life more livable in our departments, on our campuses, and at our conferences will not revolutionize civil society or higher education. But neither will our prevailing models of engaged scholarship (see Nair). We can achieve, however, a more livable life for our most vulnerable colleagues and students. By occupying the academy in ways that refuse the border between activism and our places of labor, engage in contingent acts of coalition, exploit embeddedness in ways that undermine the cruelty of the academy, and recognize the capacity of academic labor to make campuses and academic organizations more livable spaces, we can engage in modes of critique that complicate our prevailing narratives about engagement and exploit our most potent agency. 
To clarify what violating the border between engagement and the academy might entail, I offer the following theses as an incomplete manifesto on embedded activist rhetoric in the academy:

- Those of us in positions to do so should activate our departments, campuses, and disciplines by spending our (earned and unearned) professional capital on others. Impressive professional records and awards, the protection of rank and tenure, as well as the securities of whiteness, cismasculine bodies, and other privileged positionalities enable many of us to occupy academic space in ways that others cannot safely. Drawing on such capital to help professionalize and promote the work of less-privileged colleagues is one mode of activating academic space, as is leveraging professional capital to promote changes on our campuses and in our organizations. If we can wield such capital in order to receive raises and other perks, then we can also use it to pressure institutions to make changes that create more livable space for all who inhabit it.

- We must not take coalitions for granted. Rather, we should complicate the relations that we constitute at all levels of the academy, including scholar/campus, scholar/organization, and scholar/colleague relationships. We can learn here from the decolonial work of Eve Tuck and her colleagues regarding contingent collaborations. They describe such collaborations as "a counterpoint to how others have theorized solidarity and allies and require an ethic of incommensurables that recognizes what is distinct between various projects of social justice and decolonization" (57). Tuck and her coauthors explain that coalitions may form in response to specific exigencies, but are necessarily temporary due to the contingent positionalities, objectives, and therefore relations that contextualize all forms of collaboration. Thus, while many of us join forces with colleagues against administrators in contexts such as collective bargaining, we may also find ourselves relying on administrative entities such as human resources or Title IX offices to protect ourselves or others from our colleagues. In short, as scholars trained to critique the rhetorical norms of identification, we should take no professional affinity (or antagonism) for granted. ${ }^{4}$

- We can occupy and activate the limited emancipatory spaces of campuses and organizations, especially faculty senates and legislative assemblies (see Cole, Hassel, and Schell). Such spaces, while losing some institutional power, represent spaces of deliberation and democratic decision making that can pressure administrators and other entities. Recall that Harney and Moten ask us not to abandon the university entirely, but to abuse its hospitality. Leveraging sanctioned governance spaces in service of addressing real needs is one way to do this. We can also look to departmental, campus, and organizational diversity initiatives as often deeply flawed modalities for ameliorating real suffering. ${ }^{5}$ Faculty unions and advocacy organizations, for example, the American Association of University Professors, as well as academic units dedicated to area studies, can serve as invaluable spaces for 
oppositional organizing and promoting the work of historically underrepresented populations - to, in other words, constitute the undercommons.

- All of us should avoid underestimating our ability to take risks or overestimating the ability of others to do so. Understand that thresholds for risk are contingent on ways bodies are situated, but can also be a function of institutional privilege and an always-deferred promise to take more risks in the future (Yates).

- Always keep a paper trail.

The primary goal of this partial and deeply imperfect list is to serve as a heuristic for activating academic space in ways that draw on the embeddedness of the engaged scholar. Such work should always be mindful of power differentials and other variables that constrain and enable activist work on our campuses and in our organizations. Nonetheless, because we are embedded in the academy, our agency is often quite potent therein. While we cannot expect to demolish and rebuild the academy in our lifetimes, we should not underestimate our capacity to intervene and produce real consequences for real bodies.

I have not ceased caring deeply about the city and state where I live, or national and international politics. The world outside the academy still matters deeply to me, and I choose to believe it would regardless of my status as a professional scholar. My purpose in this essay is not to devalue the work of colleagues who forge meaningful relationships with communities of struggle, whether through engaged scholarship or simply because they believe it is the right thing to do. Academics belong to multiple publics that demand their attention and energy. I am arguing that those of us in rhetorical studies who also identify as activists should mobilize our critical and inventional abilities toward denaturalizing the abiding border between prevailing definitions of engagement and the space of academia itself. To claim that engagement can only take place outside the "ivory tower" presumes that our institutions are innocent and do not warrant attention compared with more conspicuously aggrieved publics. Many of our colleagues have been telling us for decades that this simply is not the case. The academy is a space of cruelty and our embeddedness therein leaves us with the choice to err on the side of complicity or resistance. Violating the borders of scholarly engagement is one strategy toward mobilizing our activist energies in ways that make the spaces of academia more humane.

\section{Notes}

1 On the 2008 NCA Convention boycott, see Cloud; Young, Battaglia, and Cloud.

2 Clarification: McGowan proposes that faculty with tenure and the rank of Associate Professor should be evaluated this way. McGowan maintains that for junior faculty, "peer review by other experts would remain crucial to being granted tenure" (417). 
3 I am indebted to D.L. Stephenson for cogently and powerfully expressing this simple truth at the 2017 NCA convention in a way that informed this chapter.

4 As I clarified with my employment of borders and cruelty, I do not draw on the conceptual resources of decoloniality lightly. I agree with Tuck and Yang that "decolonization specifically requires the repatriation of Indigenous land and life. Decolonization is not a metonymn for social justice" (21). While academia is undeniably complicit in the colonization of Indigenous peoples (Miranda), the cruelties I describe are not forms of colonization, nor is my intention to employ the vocabularies of colonized scholars as metaphors. Rather, I take Tuck's work regarding contingent collaborations, a concept firmly rooted in experiences of colonization, as instructive for other spaces of struggle. I am grateful to Darrel Wanzer-Serrano for bringing Tuck's work to my attention.

5 Recently, several NCA members submitted an open letter to the organization's Executive Committee expressing disappointment regarding the systematic exclusion of people of color from editor positions at NCA journals. While few of the signatories, myself included, have unfettered faith in NCA's commitment to racial justice or other forms of equity, we nonetheless framed our argument with the organization's espoused investments in diversity. NCA responded, offering detailed explanations about how they intended to address our concerns.

\section{Works Cited}

"Academic Freedom and Tenure: University of Nebraska-Lincoln." American Association of University Professors, May 2018, https://www.aaup.org/file/UNL_2018.pdf.

Ahmed, Sara. On Being Included: Racism and Diversity in Institutional Life. Duke UP, 2012.

Allen, Brenda. "Theorizing Communication and Race." Communication Monographs, vol. 74, no. 2, 2007, pp. 259-64.

Allen, Danielle S. Talking to Strangers: Anxieties of Citizenship since Brown v. Board of Education. U of Chicago P, 2004.

Anzaldúa, Gloria. Borderlands/La Frontera: The New Mestiza. Aunt Lute, 1999.

Arkin, William M., and Alexa O'Brien. "The Most Militarized Universities in America: A VICE News Investigation.” VICE News, 6 Nov. 2015, https://news.vice.com/article/ the-most-militarized-universities-in-america-a-vice-news-investigation.

Asante, Molefi Kete. Afrocentricity: The Theory of Social Change. Amulefi Publishing, 1980.

Baker, Kelly J. "Cruelty and Kindness in Academia." Chronicle Vitae, 11 Oct. 2016, https:// chroniclevitae.com/news/1572-cruelty-and-kindness-in-academia.

Bauer-Wolf, Jeremy. "Campus Cops Handling Racism.” Inside Higher Ed, 14 May 2018, https://www.insidehighered.com/news/2018/05/14/how-campus-police-can-deal-r acism.

Birmingham, Kevin. “"The Great Shame of Our Profession': How the Humanities Survive on Exploitation." The Chronicle of Higher Education, 12 Feb. 2017, https://www.chronicl e.com/article/The-Great-Shame-of-Our/239148.

Blair, Carole. "Contested Histories of Rhetoric: The Politics of Preservation, Progress, and Change." Quarterly Journal of Speech, vol. 78, no. 4, 1992, pp. 403-28.

Bratich, Jack Z. "From Embedded to Machinic Intellectuals: Communication Studies and General Intellect." Communication and Critical/Cultural Studies, vol. 5, no. 1, 2008, pp. 24-45.

Calafell, Bernadette Marie. "Rhetorics of Possibility: Challenging the Textual Bias of Rhetoric through the Theory of the Flesh." In Rhetorica in Motion: Feminist Rhetorical Methods and Methodologies, edited by Eileen E. Schell and K.J. Rawson. U of Pittsburgh P, 2010, pp. 104-17. 
- Monstrosity, Performance, and Race in Contemporary Culture. Peter Lang, 2015.

Campbell, Karlyn Kohrs. “The Rhetoric of Women's Liberation: An Oxymoron.” Quarterly Journal of Speech, vol. 59, no. 1, 1973, pp. 74-86.

Chávez, Karma. Queer Migration Politics: Activist Rhetoric and Coalitional Possibilities. U of Illinois P, 2013.

—. "Beyond Inclusion: Rethinking Rhetoric's Historical Narrative." Quarterly Journal of Speech, vol. 101, no. 1, 2015, pp. 162-72.

Cisneros, Josue David. The Border Crossed Us: Rhetorics of Borders, Citizenship, and Latina/o Identity. U of Alabama P, 2013.

Cloud, Dana L. "[Still] the Only Conceivable Thing to Do." [This volume.]

Cole, Kirsti, Holly Hassel, and Eileen E. Schell. "Remodeling Shared Governance: Feminist Decision Making and Resistance to Academic Neoliberalism." In Surviving Sexism in Academia: Strategies for Feminist Leadership, edited by Kirsti Cole and Holly Hassel. Routledge, 2017, pp. 13-28.

Davis, Olga Idriss. "In the Kitchen: Transforming the Academy through Safe Spaces of Resistance." Western Journal of Communication, vol. 63, no. 3, 1999, pp. 364-81.

Dutta, Mohan J. "Irrationality of Metrics and Metricide." Culture-Centered Approach, 24 Aug. 2018, http://culture-centered.blogspot.com/2018/08/irrationality-of-metricsand-metricide.html.

Enck, Suzanne Marie. "Resisting Gender Violence: We Are Also Not Alone.” Spectra, Mar. 2017, pp. 26-31.

Flores, Lisa A. "Creating Discursive Space through a Rhetoric of Difference: Chicana Feminists Craft a Homeland.” Quarterly Journal of Speech, vol. 82, no. 2, 1996, pp. 142-56.

_. "Constructing Rhetorical Borders: Peons, Illegal Aliens, and Competing Narratives of Immigration." Critical Studies in Media Communication, vol. 20, no. 4, 2003, pp. 362-87.

_. "Between Abundance and Marginalization: The Imperative of Racial Rhetorical Criticism." Review of Communication, vol. 16, no. 1, 2016, pp. 4-24.

Frey, Lawrence R. "Communication Scholarship, Civic Engagement, and Social Justice Activism." Spectra, Mar. 2017, pp. 8-13.

Gehrke, Pat J. The Ethics and Politics of Speech: Communication and Rhetoric in the Twentieth Century. Southern Illinois UP, 2009.

Gunn, Joshua, and John Louis Lucaites. "The Contest of Faculties: On Discerning the Politics of Social Engagement in the Academy." Quarterly Journal of Speech, vol. 96, no. 4, 2010, pp. 404-12.

Harney, Stefano, and Fred Moten. The Undercommons: Fugitive Planning and Black Study. Minor Compositions, 2013.

Hartnett, Stephen John. "Lincoln and Douglas Meet the Abolitionist David Walker as Prisoners Debate Slavery: Empowering Education, Applied Communication, and Social Justice." Journal of Applied Communication Research, vol. 26, no. 2, 1998, pp. 232-53.

- "Communication, Social Justice, and Joyful Commitment." Western Journal of Communication, vol. 74, no. 1, 2010, pp. 68-93.

_. "Putting NCA's Civic Callings into Action." Spectra, Mar. 2017, pp. 2-3.

Hill, Annie. "Reporting Sexual Harassment: Toward Accountability and Action." The Gender Policy Report, 19 July 2018, http://genderpolicyreport.umn.edu/reporting-sexual -harassment-towards-accountability-and-action/.

Houston, Marsha. "The Politics of Difference: Race, Class, and Women's Communication." In Women Making Meaning: New Feminist Directions in Communication, edited by Lana F. Rakow. Routledge, 1992, pp. 45-59. 
Levina, Marina. "Whiteness and the Joys of Cruelty." Communication and Critical/Cultural Studies, vol. 15, no. 1, 2018, pp. 73-8.

Loick, Daniel. "If You're a Critical Theorist, How Come You Work for a University?" Critical Horizons, vol. 19, no. 3, 2018, pp. 233-45.

McGowan, John. “An Immodest Proposal." Quarterly Journal of Speech, vol. 96, no. 4, 2010, pp. 413-20.

Millet, Kate. The Politics of Cruelty: An Essay on the Literature of Political Imprisonment. W.W. Norton, 1995.

Miranda, Deborah A. "Teaching on Stolen Ground." In Placing the Academy: Essays on Landscape, Work, and Identity, edited by Jennifer Sinor and Rona Kaufman. Utah State UP, 2007, pp. 169-87.

Morris, Charles E., III, and Thomas K. Nakayama. "Queer Editorial Overture." QED: $A$ Journal of GLBTQ Worldmaking, Inaugural Issue, 2013, pp. v-ix.

Nair, Yasmin. "The Dangerous Academic Is an Extinct Species." Current Affairs, 7 June 2017, https://www.currentaffairs.org/2017/04/the-dangerous-academic-is-an-extinct -species.

Newfield, Christopher. The Great Mistake: How We Wrecked Public Universities and How We Can Fix Them. Johns Hopkins UP, 2016.

Ono, Kent A., and John M. Sloop. "The Critique of Vernacular Discourse." Communication Monographs, vol. 62, no. 1, 1995, pp. 19-46.

Ortiz, Kasim. "On Academic Hazing, Intra-Racial Conflict, and Marginality." Conditionally Accepted, 8 Apr. 2014, https://conditionallyaccepted.com/2014/04/08/academic-h azing/.

Salaita, Steven. Uncivil Rights: Palestine and the Limits of Academic Freedom. Haymarket, 2015. Sensoy, Özlem, and Robin DiAngelo. “'We Are All For Diversity, but ...': How Faculty Hiring Committees Reproduce Whiteness and Practical Suggestions for How They Can Change." Harvard Educational Review, vol. 87, no. 4, 2017, pp. 557.

Tuck, Eve, and K. Wayne Yang. "Decolonization Is Not a Metaphor." Decolonization: Indigeneity, Education \& Society, vol. 1, no. 1, 2012, pp. 1-40.

Tuck, Eve, Mistinguette Smith, Allison M. Guess, Tavia Benjamin, and Brian K. Jones. "Geotheroizing Black/Land: Contestations and Contingent Collaborations." Departures in Critical Qualitative Research, vol. 3, no. 1, 2014, pp. 52-74.

Whitehead, Karsonya Wise. "\#BlackLivesMatter in the Classroom: Creating Spaces of Liberation and Disruption." Spectra, Mar. 2017, pp. 20-5.

Yates, Michael D. "Just Wait until I Get Tenure." CounterPunch, 4 Apr. 2017, https://ww w.counterpunch.org/2017/04/04/just-wait-until-i-get-tenure/.

Young, Anna M., Adria Battaglia, and Dana L. Cloud. “(UN)Disciplining the Scholar Activist: Policing the Boundaries of Political Engagement." Quarterly Journal of Speech, vol. 96 , no. 4, 2010, pp. 427-35. 